\title{
Mother knows best? Inhibitory maternal gatekeeping, psychological control, and the mother-adolescent relationship
}

\author{
Erin Kramer Holmes \\ Brigham Young University - Provo, erin_holmes@byu.edu \\ KayLee C. Dunn \\ Brigham Young University - Provo \\ James P. Harper \\ Brigham Young University - Provo \\ W. Justin Dyer \\ Brigham Young University - Provo \\ Randal D. Day

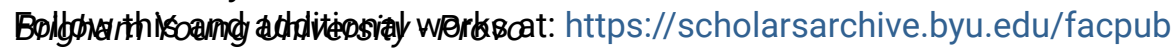 \\ Part of the Other Social and Behavioral Sciences Commons
}

\section{Original Publication Citation}

Holmes, E. K., *Dunn, K. C., Harper, J. M., Dyer, W. J., and Day, R. D. (2013). Mother knows best? Inhibitory maternal gatekeeping, psychological control, and the mother-adolescent relationship. Journal of Adolescence, 36, 91-101.

\section{BYU ScholarsArchive Citation}

Holmes, Erin Kramer; Dunn, KayLee C.; Harper, James P.; Dyer, W. Justin; and Day, Randal D., "Mother knows best? Inhibitory maternal gatekeeping, psychological control, and the mother-adolescent relationship" (2012). Faculty Publications. 4774.

https://scholarsarchive.byu.edu/facpub/4774

This Peer-Reviewed Article is brought to you for free and open access by BYU ScholarsArchive. It has been accepted for inclusion in Faculty Publications by an authorized administrator of BYU ScholarsArchive. For more information, please contact ellen_amatangelo@byu.edu. 


\title{
Mother knows best? Inhibitory maternal gatekeeping, psychological control, and the mother-adolescent relationship
}

\author{
Erin Kramer Holmes ${ }^{*, 1}$, KayLee C. Dunn ${ }^{1}$, James Harper, W. Justin Dyer, Randal D. Day \\ School of Family Life, Brigham Young University, 2092C JFSB, Provo, UT 84602, United States
}

Keywords:

Maternal gatekeeping

Parent-child relationships

Psychological control

Family systems

\begin{abstract}
A B S T R A C T
We used structural equation modeling to explore associations between inhibitory maternal gatekeeping attitudes, reports of inhibitory maternal gatekeeping behaviors, maternal psychological control, observed mother-adolescent warmth, and adolescent reports of maternal involvement. Our random stratified sample consisted of 315 mothers and their adolescents. Results revealed that inhibitory maternal gatekeeping attitudes were positively associated with reports of inhibitory gatekeeping behaviors. Psychological control fully mediated the relationship between inhibitory gatekeeping attitudes, reports of inhibitory gatekeeping behaviors, and adolescent reports of maternal involvement. Though gatekeeping attitudes and behaviors were not associated with observed motheradolescent warmth, psychological control was negatively associated with observed mother-adolescent warmth. Thus, although prior research emphasized the negative effects of inhibitory gatekeeping on father-child relationships, the present research elucidates that in conjunction with psychological control, inhibitory gatekeeping negatively influences the mother-adolescent relationship. All findings are discussed in the context of family systems theory.

( 2012 The Foundation for Professionals in Services for Adolescents. Published by Elsevier Ltd. All rights reserved.
\end{abstract}

It is clear that mother-adolescent relationship quality impacts adolescent development. For example, a positive motheradolescent relationship is correlated with lower levels of internalizing and externalizing behaviors (Kim \& Cicchetti, 2004), lower rates of risky sexual behaviors (Jaccard, Dittus, \& Gordon, 1996), and higher levels of prosocial behaviors and hope (Day \& Padilla-Walker, 2009). It is also clear that coparenting is an important predictor of parent-child relationship quality (Feinberg, 2002), with evidence suggesting that coparenting interactions have greater impact on child well-being than marriage does (McHale, 2009, pp. 77-94; Teubert \& Pinquart, 2010). Yet coparenting interactions are not commonly explored as correlates of mother-adolescent relationship quality (Feinberg, Kan, \& Hetherington, 2007).

One key coparenting construct is called maternal gatekeeping. Maternal gatekeeping includes elements of control, and reflects a mother's encouraging and/or discouraging regulatory attitudes and behaviors toward her partner (Allen \& Hawkins, 1999; Schoppe-Sullivan, Cannon, Brown, Mangelsdorf, \& Sokolowski, 2008). For example, a mother may be gatekeeping her husband's fathering efforts when she re-does what he previously did, or when she decides she is the only one who can perform a particular task for her child. Prior research established that when inhibitory maternal gatekeeping is present in coparenting practices, father involvement and father-child relationship quality decrease (Allen \& Hawkins, 1999; Fagan \& Barnett, 2003; McBride et al., 2005). Unfortunately, no research has explored the impact of maternal gatekeeping on the

\footnotetext{
* Corresponding author. Tel.: +1 8014225435.

E-mail address: erin_holmes@byu.edu (E.K. Holmes).

1 These authors contributed equally to this manuscript.
} 
mother-child relationship. Further, understanding the mechanisms by which gatekeeping attitudes and behaviors might impact the mother-child relationship is also needed. We suggest that gatekeeping in the coparental subsystem may be associated with other controlling or regulatory behaviors in a mother's parenting, such as psychological control. Thus, in the present study, we expand the current parent-adolescent literature by exploring the relationship between inhibitory maternal gatekeeping, maternal psychological control, mother-adolescent warmth, and mother-adolescent involvement.

\section{Literature review}

Family systems theory

Family systems theory provides a valuable framework for understanding associations between gatekeeping, psychological control, and mother-adolescent relationship quality. Three family systems assumptions inform our current project. First, family systems theorists assert that a family is a unit of interdependent individuals (Broderick, 1993). Within this unit, the functioning of the individuals is related to the individuals themselves and to the system of behaviors between members of the family. Thus, the mother-adolescent relationship will likely be related to a mother's perceptions of her gatekeeping attitudes, the adolescent's perceptions of the mother's psychologically controlling behaviors, the adolescent's report of the motheradolescent relationship, and observations of mother-adolescent interaction.

Second, the family system is composed of interdependent subsystems, such as the parent-adolescent relationship and the coparental relationship. Systems theorists stress that the functioning of one subsystem will influence the functioning of another (Lindsey \& Caldera, 2006; Minuchin, 1974, 1985). Thus, based on the principles of family systems theory, the presence of maternal gatekeeping in the coparental subsystem will likely impact interactions in parent-adolescent subsystems as well. Current evidence supports this claim by establishing a significant association between gatekeeping and the father-child relationship (DeLuccie, 1995; Schoppe-Sullivan et al., 2008), with findings that inhibitory gatekeeping is detrimental to the father-child relationship (Allen \& Hawkins, 1999; Fagan \& Barnett, 2003). The present study expands this work by questioning whether or not the presence of maternal gatekeeping further impacts the mother-child relationship.

Third, family systems theory assumes that processes linking individual and relational characteristics within the family system reflect both direct and indirect pathways between constructs. Thus it is likely that the effects of gatekeeping on mother-adolescent relationship quality will be based not only on direct processes, but also on indirect processes. In the present study we explore whether or not a mother exercising regulatory control in the coparental dyad through her gatekeeping attitudes and behaviors will be related to exercising control in other aspects of her family interactions, such as displaying psychologically controlling behaviors with her adolescent. We hypothesize that associations between inhibitory gatekeeping and the mother-adolescent relationship will be mediated by maternal psychological control.

\section{Maternal gatekeeping}

Maternal gatekeeping has been explored over the past two decades (Allen \& Hawkins, 1999; DeLuccie, 1995). Researchers frequently conceptualize maternal gatekeeping in terms of attitudes and behaviors, distinguish between inhibitory and facilitative dimensions of gatekeeping, and discuss gatekeeping in the context of a mother's desire for control or regulation of her partner's parenting efforts. Maternal gatekeeping attitudes consist of mothers' self-imposed standards and responsibilities, maternal identity confirmation, and differentiated gender roles (Allen \& Hawkins, 1999). Maternal gatekeeping behaviors consist of the behaviors mothers use to restrict or facilitate fathers' access to their children (Fagan \& Barnett, 2003).

Researchers have further identified important distinctions between inhibitory gatekeeping or gate closing (behaviors and attitudes that hinder a father's involvement in family work) and maternal facilitation or gate opening (behaviors and attitudes that encourage a father's involvement in family work) (Cannon, Schoppe-Sullivan, Mangelsdorf, Brown, \& Sokolowski, 2008; Schoppe-Sullivan et al., 2008; Trinder, 2008). While researchers include both facilitative and inhibitory practices (Puhlman \& Pasley, 2010; Sano, Richards, \& Zvonkovic, 2008), the data reported here focus specifically on inhibitory gatekeeping and its influence on the mother-child relationship.

More recently, both inhibitory and facilitative gatekeeping have been conceptualized in the context of control. This conceptualization has emphasized that maternal gatekeeping is not simply an individual process; it is a dyadic one between mothers and fathers that stems from a mother's desire to regulate how she and her partner interact with their child (Adamsons, 2010). For instance, gatekeeping regulates fathers' active involvement with their children (Gaunt, 2008; Herzog, Umana-Taylor, Madden-Derdich, \& Leonard, 2007; Sano et al., 2008; Schoppe-Sullivan et al., 2008), fathers' parenting behaviors (Cannon et al., 2008; McBride et al., 2005), and fathers' accessibility to their children (McBride et al., 2005; Roy \& Dyson, 2005). In these situations mothers regulate, or attempt to control the ways fathers are involved in families.

It is possible that the meaning and implications of maternal gatekeeping may change from childhood to adolescence. Whereas most coparenting research has focused on developmentally appropriate outcomes for infancy and childhood, over the past five years coparenting researchers have begun to establish that coparenting conflict increases adolescent risky behavior (Baril, Crouter, \& McHale, 2007), increases adolescent anti-social behavior (Feinberg et al., 2007), increases parental negativity (Feinberg et al., 2007), but may produce smaller effects on adolescents than on children (Teubert \& Pinquart, 2010). 
Unfortunately, the expansion of coparenting research into adolescence has not yet included much work on maternal gatekeeping and adolescent development. The only literature that currently exists focuses on adolescent parents, and suggests that adolescent parents engage in gatekeeping attitudes and behaviors similar to those of adult parents, with comparable detrimental effects of inhibitory gatekeeping on father and child outcomes (Fagan \& Barnett, 2003; Futris \& Schoppe-Sullivan, 2007; Herzog et al., 2007). The lack of research on the effects of maternal gatekeeping during adolescence further supports the need for research exploring the impact of gatekeeping on parent-adolescent relationships.

\section{Maternal gatekeeping and the mother-child relationship}

The father-child relationship has been the primary outcome of interest in gatekeeping research to date. Yet, family systems theory suggests that the presence of gatekeeping attitudes or behaviors in the system will likely affect multiple elements of the family. Empirical assessments have further established that the quality of coparental interactions is associated with parent-child relationship quality for both mothers and fathers (Cox, Paley, \& Harter, 2001; Teubert \& Pinquart, 2010), therefore both theoretical and empirical support suggest that the presence of gatekeeping within the family system will likely influence mother-child relationship quality. Despite evidence that gatekeeping impacts the father-child subsystem, no empirical exploration of the effects of gatekeeping on the mother-child relationship exist.

\section{Assessing the mother-child relationship}

Two common assessments of the mother-child relationship include dyadic observations of parental warmth and individual reports of parental involvement (often reports from the mother or from the child). Parental warmth is an agreed upon measurement of mother-child relationship quality (Gray \& Steinberg, 1999). Researchers report that warmth within the parent-child dyad can enable both mother and adolescent to successfully move through difficult aspects of adolescence (Laursen \& Collins, 2009). Also, parental warmth is associated with a decrease in delinquency and an increase in self-esteem and school work outcomes over time (Doyle \& Markiewicz, 2005).

Equal to warmth, parental involvement is also an important component of the parent-child relationship and adolescent outcomes (Pleck, 2010; Wenk, Hardesty, Morgan, \& Blaire, 1994). Parental involvement is negatively correlated with adolescent behavior problems (Amato \& Rivera, 1999), positively correlated with adolescent prosocial behaviors (Day \& Padilla-Walker, 2009), and maternal involvement is positively correlated with father involvement (Pleck \& Hofferth, 2008). For the purposes of this paper, observed warmth and adolescent report of maternal involvement will be presented as constructs of the mother-child relationship.

\section{Potential mediation: maternal psychological control}

Psychologically controlling behaviors reflect intrusive parenting methods whereby the parent manipulates and invalidates the child's emotional experiences, and may reflect behaviors such as generating guilt, shaming, and inciting anxiety (Barber, 1996). Thus far, psychological control has been correlated with a host of negative adolescent outcomes such as delinquent behavior (Doyle \& Markiewicz, 2005), depression and loneliness (Barber, Stolz, \& Olsen, 2005; Soenens, Park, Vansteenkiste, \& Mouratids, 2012), reactive aggression (Rathert, Fite, \& Gaertner, 2011), adjustment problems (Conger, Conger, \& Scarmella, 1997; Gray \& Steinberg, 1999), and a decrease in basic emotional functioning (Wang, Pomerantz, \& Chen, 2007).

Psychological control has also played an important mediating role in the intergenerational transmission of maladaptive perfectionism (Soenens et al., 2005), and associations between maladaptive perfectionism and adolescent well-being (Soenens, Vansteenkiste, Duriez, \& Goossens, 2006), and has been linked with coparental and marital dynamics (Krishnakumar, Buehler, \& Barber, 2003; Pettit \& Laird, 2002; Pettit, Laird, Dodge, Bates, \& Criss, 2001). Given that coparental dynamics have been connected to psychological control we raise the question here whether the coparental dynamics evidenced in inhibitory gatekeeping may spill over into childrearing practices. We base our claim on Soenens et al.'s (2005) research which established that parents who pursue their own goals rigidly, and who critically evaluate their child's behavior also tend to use psychological control. Recently, such perfectionism has been correlated with inhibitory maternal gatekeeping and is evidenced in inhibitory gatekeepers' need for control, desire for external maternal identity confirmation, and exceedingly high standards for housework and childrearing (Lee, Bartholomew, SchoppeSullivan, \& Kamp Dush, 2011).

\section{Purpose of the study and hypotheses}

The purpose of this study is to investigate the relationship between inhibitory maternal gatekeeping attitudes, reports of inhibitory maternal gatekeeping behaviors, observed mother-adolescent warmth, and the adolescent's report of maternal involvement. We hypothesize gatekeeping attitudes regarding standards and responsibilities will be positively associated with gatekeeping behaviors. We further hypothesize that reports of inhibitory gatekeeping behaviors will be negatively associated with adolescent reports of maternal involvement and observed reports of maternal 
warmth in the parent-adolescent dyad. Finally, we hypothesize that maternal psychological control will mediate the association between gatekeeping behaviors and each assessment of mother-adolescent relationship quality. (Please see Fig. 1)

\section{Method}

Participants

Study participants come from the Flourishing Families Project (FFP), a study of family process involving families with a child between age 10 and 14 years old at baseline. Using a random-stratified sample to improve generalizability and to ensure that this sample reflected the multi-ethnic and family structure of the city, five hundred families from a large city in the Northwestern United States agreed to participate.

The final sample for this paper consisted of 315 intact families with complete data (none of the 151 single-parent families reported on gatekeeping practices, and another 34 families had incomplete data preventing us from using them in the bootstrap analysis for mediation). Our sample included the adolescent child (mean age $=12.28, \mathrm{SD}=.99 ; 49.5 \%$ male and $50.5 \%$ female), and the mother (43.57 years of age, SD $=5.54)$. The families in this sample are mostly Caucasian (74.6\%), with 6.3\% African American, and 19.1\% of other ethnicity. They are mostly college educated with 66.7\% graduating from college, 26.3\% taking some college, 5.1\% graduating from high school, and only $1.9 \%$ with less than a high school education. The families in this sample are primarily middle-class, making a combined income of at least $\$ 80,000$ a year (72.1\%). These demographics accurately represent the two-parent families in this geographic area. (See Table 1.)

\section{Procedure}

Families were primarily recruited using a purchased national telephone survey database (Polk Directories/InfoUSA). Identified families were randomly selected from targeted census tracts that mirrored the socio-economic and racial stratification of reports of local school districts. Of the 692 eligible families contacted, 500 agreed to participate, resulting in a $72 \%$ response rate (Day et al., 2009). Once eligibility and consent were established, interviewers made an appointment to come to the family's home to conduct an assessment interview that included a battery of questionnaires, and four, 9 min video-taped dyadic interactions. During the interactions, dyads were provided with a set of discussion cards that have been used for parent-child discussion tasks in numerous published studies by the Iowa Behavioral Coding lab (Melby et al., 1998 ) since 1989. The questions used in the discussion task asked the mother and child to address characteristics that naturally occur in parentchild relationships, such as, "What do we think we will do together tomorrow?, How does mom want me to act?, What does mom do when I do something she doesn't like?, and What was one of the last things that caused problems or disagreements between the two of us? What did each of us do or say?" They were instructed to take turns (cards were clearly marked adult or youth on the back) so each could participate in reading questions, and were asked to discuss each other's answers and to move to the next question when they both felt finished. While the pairs discussed the cards in front of the video camera, no researchers or other family members were allowed in the room. The videotaped interactions were coded by trained coders.

MOTHER KNOWS BEST? 35

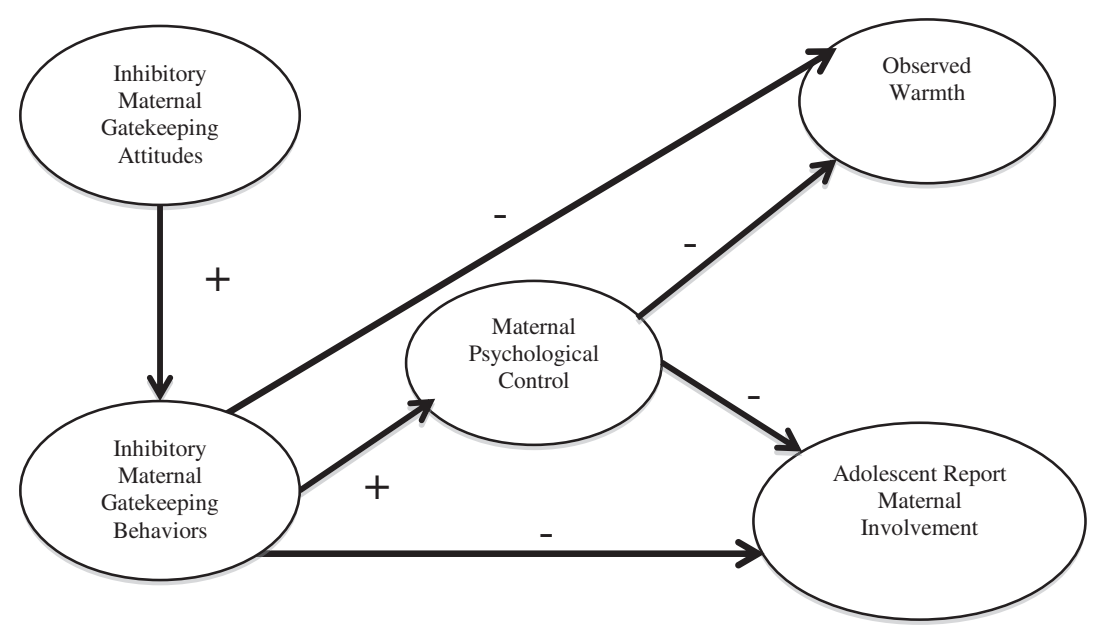

Fig. 1. Hypothesized model, showing the mediation of psychological control and maternal gatekeeping attitudes, maternal gatekeeping behaviors, observed warmth, and adolescent report of maternal involvement. 
To establish concurrent criterion validity Melby, Conger, and Puspitawait (1999) correlated observer ratings of adolescent behaviors from the same discussion task used in our study with self, sibling, and parent reports of behaviors and found strong correlations among these various indicators. Further, using the same discussion questions, Scaramella, Conger, Spoth, and Simons (2002) also used behavior ratings as well as parents' and children's self-reports of parents' behaviors and found correlations ranging from .74 to .82. To further establish validity, Melby, Hoyt, and Bryant (2003) used these same discussion questions to assess the effects of ethnicity on observer ratings and found that systematic bias was absent.

\section{Measures}

\section{Maternal gatekeeping attitudes}

To determine the mother's level of inhibitory maternal gatekeeping attitudes, we created a latent construct by compiling five items from the Standards and Responsibilities subscale of Allen and Hawkins (1999) gatekeeping measure. Items used to construct this scale were, "It is too hard to teach family members the skills necessary to do the jobs right, so I'd rather do them myself," "My spouse doesn't really know how to do a lot of household chores... so it is just easier if I do them," "I have higher standards than my spouse for how well cared for the house should be," "I frequently re-do household tasks my spouse has not

Table 1

Means, standard deviations, and factor loadings for all measured variables.

\begin{tabular}{|c|c|c|c|}
\hline Variables & Mean or \% & SD & Factor loadings \\
\hline \multicolumn{4}{|l|}{ Latent variables } \\
\hline \multicolumn{4}{|l|}{ Maternal gatekeeping attitudes } \\
\hline Re-do household tasks & 1.92 & .88 & .70 \\
\hline Rather do tasks than teach them & 1.89 & .72 & .58 \\
\hline Spouse doesn't know how & 1.59 & .80 & .76 \\
\hline Higher standards than spouse at home & 2.25 & 1.1 & .59 \\
\hline I like being in charge at home & 2.16 & .95 & .57 \\
\hline \multicolumn{4}{|l|}{ Maternal reports of gatekeeping behaviors } \\
\hline I discipline child not spouse & 2.53 & 1.10 & .55 \\
\hline I comfort child not spouse & 2.15 & .97 & .65 \\
\hline I take child to doctor not spouse & 2.81 & 1.26 & .59 \\
\hline I make decisions for child, not spouse & 2.09 & .95 & .89 \\
\hline I talk to child about behavior, not spouse & 2.08 & .88 & .92 \\
\hline \multicolumn{4}{|l|}{ Observed warmth } \\
\hline Maternal endearment & 1.61 & 1.10 & .73 \\
\hline Maternal escalate warmth & 3.25 & 1.45 & .59 \\
\hline Child endearment & 1.10 & .47 & .41 \\
\hline Child escalate warmth & 1.37 & .84 & .58 \\
\hline \multicolumn{4}{|l|}{ Adolescent report maternal involvement } \\
\hline Gives me encouragement & 4.42 & .81 & .63 \\
\hline Makes it easy to talk with her & 4.19 & .98 & .82 \\
\hline Does activities with me & 3.60 & 1.12 & .61 \\
\hline \multicolumn{4}{|l|}{ Maternal psychological control } \\
\hline Parent tries to change how I feel or think & 2.45 & 1.13 & .47 \\
\hline Parent interrupts me & 2.08 & 1.08 & .64 \\
\hline Parent is less friendly & 1.62 & 1.62 & .76 \\
\hline Parent stops talking to me & 1.40 & 1.40 & .52 \\
\hline \multicolumn{4}{|l|}{ Control variables } \\
\hline \multicolumn{4}{|l|}{ Gender } \\
\hline Male & $49.5 \%$ & & \\
\hline Female & $50.5 \%$ & & \\
\hline Age & 12.28 & .99 & \\
\hline \multicolumn{4}{|l|}{ Family ethnicity } \\
\hline Caucasian & $74.6 \%$ & & \\
\hline African American & $6.3 \%$ & & \\
\hline Other & $19.1 \%$ & & \\
\hline \multicolumn{4}{|l|}{ Maternal education } \\
\hline Less than high school & $1.9 \%$ & & \\
\hline High school graduate & $7.0 \%$ & & \\
\hline Some college & $26.3 \%$ & & \\
\hline College graduate & $66.7 \%$ & & \\
\hline \multicolumn{4}{|l|}{ Family income } \\
\hline At least $\$ 20,000$ & $3.5 \%$ & & \\
\hline At least $\$ 40,000$ & $8.3 \%$ & & \\
\hline At least $\$ 60,000$ & $16.2 \%$ & & \\
\hline At least $\$ 80,000$ & $16.8 \%$ & & \\
\hline At least $\$ 100,000$ & $17.8 \%$ & & \\
\hline At least $\$ 120,000$ & $14.3 \%$ & & \\
\hline$\$ 120,000$ or more & $23.2 \%$ & & \\
\hline
\end{tabular}


done well," and "I like being in charge when it comes to domestic responsibilities." Possible Likert-type responses ranged from 1 (not at all like me) to 4 (very much like me). High scores indicate higher levels of maternal gatekeeping attitudes. Cronbach's alpha for these combined items was .78. The factors loaded with scores from .58 to .76. These loadings meet acceptable standards for the creation of unobserved variables (Kline, 2011).

\section{Reports of maternal gatekeeping behaviors}

We created the maternal gatekeeping behaviors latent construct using five items from the gatekeeping behaviors measurement (Fagan \& Barnett, 2003). Items included, "If my child needs to be disciplined, I think that I am the one to discipline them, not their father," "If my child's feelings are hurt, I think that I should comfort them, not their father," "If my child has to go to the doctor, I think that I am the one to take them, not their father," "If a decision has to be made for my child, I think that I am the one to make it, not their father, " and "If an adult needs to talk to my child about their behavior, I think that I am the one to do the talking, not their father." Mothers responded on a five point Likert-type scale ranging from 1 (strongly disagree) to 5 (strongly agree). Higher scores indicate a higher level of maternal gatekeeping behaviors. Cronbach's alpha for these combined items was .84. The factors loaded with scores from .55 to .92 . These factor loadings met acceptable standards for the creation of an unobserved variable (Kline, 2011).

\section{Observed warmth}

To minimize shared method variance, we created a latent construct representing observed mother-adolescent relationship quality using four observed dyadic variables taken from the Iowa Family Interaction Rating Scales (IFIRS, Melby et al., 1998): mother's endearment, mother's escalate warmth, adolescent's endearment, and adolescent's escalate warmth (please see the "Procedure" section above for a description of the task). These codes represent a family systems orientation by offering a snapshot of dyadic characteristics in the mother-child relationship. Our coding scheme includes both the mother and child behaviors toward each other Endearment behaviors consist of verbal expressions of personalized and unqualified approval of the other person. Endearments also convey extreme commitment and global compliments regarding the other person. Escalate warmth behaviors consist of the individual's tendency to escalate his/her own warm and/or supportive behaviors directed toward another participant. An escalation is defined as one warm behavior built upon another or an intensification of a warm behavior. Coders gave each participant a score from 1 (no signs) to 9 (frequently shows signs) on each of the four scales. Intraclass correlations for mother endearment $=.92$; for adolescent endearment $=.83$; for mother escalate warmth $=.90$; and for adolescent escalate warmth $=.87$. We used factor analysis to determine how mother-adolescent dyadic codes reflecting warm and supportive behaviors loaded onto one factor. We then chose those with the highest loadings to use as indicators of the latent variable, "observed warmth", in our structural equation model. The factors loaded from .41 to .73, meeting acceptable standards (Kline, 2011).

\section{Adolescent report maternal involvement}

We measured maternal involvement in the adolescent's life with three items taken from the Inventory of Father Involvement (Hawkins et al., 2002). The target adolescent responded to questions concerning mother involvement on a 5-point Likert scale ranging from 1 (never) to 5 (always). Higher scores indicate higher levels of maternal involvement. Items include, "Does your mother give you encouragement?" "Does your mother make it easy to talk to you?" and "Does your mother do activities with you besides watch TV?" Cronbach's alpha for these combined items was .73. Factor loadings for this scale met acceptable standards (Kline, 2011) ranging from .61 to .82 .

\section{Maternal psychological control}

We created a latent variable using four items from the Child Report of Parent Behavior Inventory (CRPBI; Barber, 1996) to measure mother's psychological control. Items include, "My mother tries to change how I feel or think about things," "My mother interrupts me," "My mother is less friendly with me if I do not see things her way," and "If I have hurt her feelings, my mother stops talking to me until I please her again." Higher scores indicated higher levels of psychological control as adolescents responded to this survey on a five point Likert-type scale ranging from 1 (never) to 5 (very often). Cronbach's alpha was .68. The factors loaded with scores from .47 to .76. Factor loadings for this scale met acceptable standards (Kline, 2011).

\section{Control variables}

The control variables used in this study were adolescent gender, adolescent age, family ethnicity, maternal education, and combined family income. The child reported on his or her gender and age. Both mother and child were asked to report on their ethnicity, and the family ethnicity categorical variable was created by compiling mother and child reports. The number of respondents of Asian, Hispanic, other, and mixed ethnicities were too low to create separate categories, so they were combined into one "other ethnicity" category. Thus family ethnicity represents three categories: White, as a reference group, African American, and Other. Mothers reported on both family income and maternal education.

\section{Data analysis}

Data for this study were analyzed using the Analysis of Moments Structures (AMOS) software, Version 18.0 (Arbuckle, 2010). Using structural equation modeling (SEM) was beneficial because it allowed us to test and refine our theoretical 
model, minimize bias (i.e. Type 1 error) in estimates, and distinguish between both direct and indirect relationships specified in our model, all based on confidence intervals and other assessments of goodness of fit for hypothesis testing (Buhi, Goodson, \& Neilands, 2007). Goodness of fit indexes compare the observed covariances with the covariances predicted by the hypothesized model. Assessments of "goodness of fit" include the chi-square $\left(\chi^{2}\right)$ test, the Root Mean Square Error of Approximation (RMSEA), and baseline comparison indexes such as the Tucker-Lewis Index (TLI) or Comparative Fit Index (CFI). $\chi^{2}$ examines whether or not there is a statistically significant difference between the model and the sample data and degrees of freedom. A non-significant $\chi^{2}$ statistic is preferable as it reflects "exact fit" between the hypothesized model and the data. The RMSEA reflects good model fit with a score of .06 or lower (the lower the better), while the TLI/CFI reflect good model fit with a score of .95 or higher (on a scale of 0-1) (Hu \& Bentler, 1999).

Building a sound structural equation model is often referred to in two steps: 1) building and refining the measurement model, and 2) testing and refining the structural model. By creating latent variables in the measurement model, we were able to create more representative constructs of the variables under study, free of random error (Kline, 2011).

\section{Results}

Using AMOS 18.0 we constructed a structural equation model to evaluate the associations between inhibitory maternal gatekeeping attitudes, reports of maternal gatekeeping behaviors, psychological control, observation of mother-child warmth, and adolescent reports of mother-child relationship quality (see Fig. 2). We used three fit indices to evaluate model fit. We found that the model fit the data well: $\chi^{2}=310.68, d f=274, p=.06, C F I=.98, R M S E A=.02(l o=.00$, hi $=.03)(\mathrm{Hu} \&$ Bentler, 1999).

Age and family ethnicity were the only control variables that were significantly associated with the latent variables in the model. Older adolescents in this sample reported less maternal involvement than younger adolescents $(\beta=-.14, p<.05)$. African American adolescents reported lower levels of maternal involvement $(\beta=-.17, p<.01)$, and were observed in less warm mother-adolescent interaction $(\beta=-.14, p<.05)$.

After controlling for gender, age, maternal education, family income, and family ethnicity, consistent with our first hypothesis, inhibitory maternal gatekeeping attitudes significantly predicted inhibitory maternal reports of gatekeeping behaviors $(\beta=.22, p<.01)$. Having higher standards and responsibilities for childrearing and one's household is correlated with a mother's higher likelihood to control or regulate parenting interactions.

We found partial support for our hypothesis that maternal reports of gatekeeping behavior would impact the motherchild relationship. Reports of inhibitory maternal gatekeeping behavior were not associated with observed maternal warmth $(\beta=-.05, p=.84)$. Maternal gatekeeping behaviors were, however, significantly related to adolescent reports of maternal involvement $(\beta=-.09, p<.05)$. When mothers reported higher inhibitory gatekeeping behaviors, their adolescents reported lower maternal involvement in the adolescent's life.

\section{MOTHER KNOWS BEST? 36}

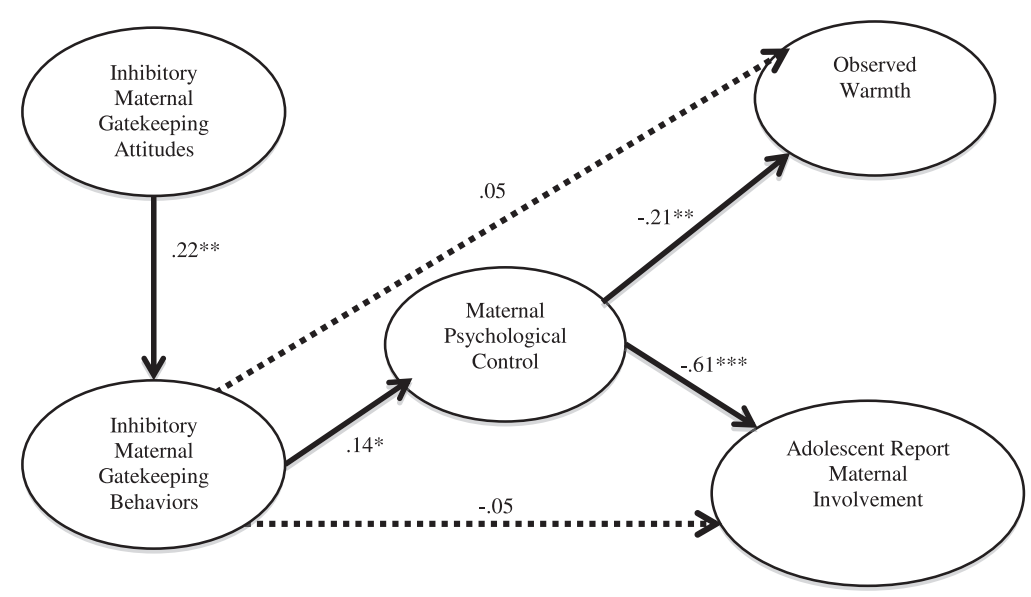

$$
\begin{aligned}
& \text { Model Fit: } x^{2}=310.68, d f=274, p<.06, C F I=.98, R M S E A=.02(\text { lo }=.00 ; \text { hi }=.03) \\
& { }^{*} p<.05 ; * * p<.01 ; * * * p<.001 .
\end{aligned}
$$

Fig. 2. SEM, results showing standardized effects for the mediation of psychological control and maternal gatekeeping attitudes, maternal gatekeeping behaviors, observed warmth, and adolescent report of maternal involvement. 
We next tested our hypothesis that maternal psychological control mediated the relationship between gatekeeping and mother-child relationship outcomes (see Table 2 for a decomposition of standardized effects). As recommended in the structural equation modeling literature (MacKinnon, 2008; Preacher \& Hayes, 2008), we examined mediation by testing the indirect effects in the model using bias-corrected bootstrap analysis. We used bias-corrected estimates because MacKinnon (2008) suggests they are more reliable. Confidence limits were estimated on the basis of 2000 bootstrap samples. First we found that the direct association between maternal gatekeeping behaviors and psychological control was significant $(\beta=.14$, $p<.05)$. The association between psychological control and observed warmth was also significant $(\beta=-.21, p<.01)$, as were the association between psychological control and reports of maternal-adolescent involvement $(\beta=-.61, p<.001)$.

Consistent with our hypotheses, we found that the indirect association between inhibitory maternal gatekeeping attitudes on psychological control through maternal gatekeeping behaviors was significant $(p<.05)$ with a confidence interval of [.003, .096].

Also consistent with our hypothesis, we found an indirect association between inhibitory maternal gatekeeping attitudes on the adolescent report of maternal involvement through behaviors and psychological control $(p<.05)$ with a confidence interval of $[-.057,-.002]$. The indirect association between maternal report of inhibitory gatekeeping behaviors and adolescent report of maternal involvement through psychological control displayed significant mediation $(p<.05)$, with a confidence interval of $[-.132,-.004]$. Finally, we did not find mediation from the indirect effects of maternal gatekeeping attitudes on observed warmth through behaviors and psychological control [-.039, .052].

\section{Discussion}

The purposes of this study were two-fold. First, we tested a structural equation model hypothesizing that there would be relationships between inhibitory maternal gatekeeping attitudes, reports of inhibitory maternal gatekeeping behaviors, and the mother child relationship. Second, we tested the possible mediating role of psychological control on the mother-child relationship. Based on the literature, we hypothesized that inhibitory maternal gatekeeping attitudes and behaviors would negatively influence the mother-child relationship through a mechanism of psychological control.

Our results expanded the current body of literature in four important ways. First, we are the first authors we know of to test the empirical association between maternal gatekeeping attitudes and behaviors. We found that mothers' high standards and responsibilities for childrearing and housework do predict their inhibitory gatekeeping coparental behaviors. In other words, mothers who tend to hold high personal standards regarding childrearing are likely to regulate or control others in the family system. Second, we found that when a mother's maternal gatekeeping attitudes are strong enough to elicit maternal gatekeeping behaviors, her adolescent is likely to report a decrease in maternal involvement with the adolescent. Third, maternal reports of inhibitory gatekeeping behaviors are linked with adolescent reports of maternal psychological control. Fourth, through the important mediating mechanism of maternal psychological control, maternal gatekeeping attitudes and behaviors impact adolescent perceptions of maternal involvement.

These findings hold a few implications for future research. First, researchers at this point frequently fail to distinguish between maternal gatekeeping attitudes and behaviors. Thus, studies currently investigating gatekeeping behaviors may be failing to recognize how gatekeeping attitudes may be a predetermining factor in that relationship; or those studies that emphasize gatekeeping attitudes may be missing an important part of how attitudes translate themselves into key behaviors in coparenting and maternal practice. As the translation of attitudes into behaviors becomes especially critical for clinical work with families (e.g. cognitive behavioral therapies), we suggest continued research explore links between maternal gatekeeping attitudes and behaviors.

Table 2

Decomposition of effects on inhibitory maternal gatekeeping behaviors, psychological control, observed warmth, and adolescent report of maternal involvement.

\begin{tabular}{|c|c|c|c|}
\hline Variable & Indirect & Direct & Total \\
\hline Gatekeeping attitudes on behaviors & - & $.22^{* *}$ & $.22^{* *}$ \\
\hline Gatekeeping attitudes on psychological control & .03 & - & .03 \\
\hline Gatekeeping attitudes on observed warmth & .01 & - & .01 \\
\hline Gatekeeping attitudes on maternal involvement & -.03 & - & -.03 \\
\hline Gatekeeping behaviors on psychological control & - & $.14^{*}$ & $.14^{*}$ \\
\hline Gatekeeping behaviors on maternal involvement & -.09 & -.05 & $-.14^{*}$ \\
\hline Gatekeeping behaviors on observed warmth & -.03 & .05 & -.03 \\
\hline Psychological control on observed warmth & - & $-.21^{* *}$ & $-.21^{* *}$ \\
\hline Psychological control on maternal involvement & - & $-.61^{* * *}$ & $-.61^{* * *}$ \\
\hline \multicolumn{4}{|l|}{ Control variables } \\
\hline Age on maternal involvement & -.06 & $-.14^{*}$ & $-.20^{* *}$ \\
\hline African American on maternal involvement & -.03 & $-.17^{*}$ & $-.20^{* *}$ \\
\hline African American on observed warmth & -.01 & $-.14^{*}$ & $-.15^{*}$ \\
\hline
\end{tabular}

Notes. $N=315$. Bootstrap bias-corrected $p$-values: ${ }^{*} p<.05,{ }^{* *} p<.01,{ }^{* * *} p<.001$. Indirect and direct effects may not sum to total due to rounding. All estimates regressed on gender, age, maternal education, ethnicity, and family income. Only significant controls reported in this table. 
Second, although prior researchers have studied the interrelation between maternal gatekeeping and father-child relationship quality (Allen \& Hawkins, 1999; Fagan \& Barnett, 2003; Gaunt, 2008; Herzog et al., 2007; McBride et al., 2005; Sano et al., 2008; Schoppe-Sullivan et al., 2008), our investigation has shown that when the mother asserts control over the father's involvement in family work, it has complicated influences on the mother-child dyad as well. When mothers behaviorally constrict or control fathers' involvement in family work, and these mothers in turn engage in psychologically controlling behaviors, adolescents report that their mothers are less involved in their lives. These findings fall in line with family systems theory which indicates that interactions within coparental subsystems can influence parent-child subsystems within the same unit (Minuchin, 1974).

Third, we found that inhibitory maternal gatekeeping attitudes and behaviors are linked to psychologically controlling behaviors. Allen and Hawkins (1999) suggested that inhibitory maternal gatekeeping reflects a mother's desire for sole managerial ownership over family work in her home. We questioned whether maternal gatekeeping behaviors were related to other components of control in her childrearing practices. By adding a second inhibitory aspect of control into the model (i.e. psychological control of child (Barber, 1992)), we found that a mother's control of a father's parenting behavior is also related to the psychological control of her child. Her inhibitory gatekeeping practices and her maternal psychological control both appear to undermine the quality of relationships she is able to have within her family Consistent with a family systems perspective, because interparental exchanges related to childrearing have a greater impact on children's well-being than exchanges not related to childrearing, understanding associations between maternal gatekeeping attitudes, maternal gatekeeping practices, and coparenting processes matters not only for parents but also for adolescents.

Fourth, our results indicate that in conjunction with psychologically controlling behaviors, inhibitory gatekeeping attitudes and behaviors have a negative influence on the mother-child relationship, particularly maternal involvement with her adolescent. Interestingly, these results may seem counterintuitive to some. Mothers are often sociologically conditioned by scientific management or home management perspectives to believe that holding strict standards and executing structured plans for their homes is what "good" mothers do (Allen \& Hawkins, 1999; Beutler, Burr, Bahr, \& Herrin, 1989). Nevertheless, the findings in our study indicate that according to adolescents, inhibitory gatekeeping mothers are actually less involved with their adolescents. It appears that in accordance with systems theory (Minuchin, 1974), when a mother behaves in ways that impose control over the father's involvement with the child, she may negatively influence her relationship with the child as well.

Fifth, as recent research indicates that perfectionism is a precursor to gatekeeping (Lee et al., 2011), it may also be that mothers who are focused on maintaining standards in their homes spend more time maintaining the rules and less time focusing on the emotional needs of their adolescent child, thus diminishing their involvement in their adolescent's life.

Finally, neuroticism, poor marital quality, and other dimensions of coparenting such as coparenting conflict may also impact a mother's inhibitory gatekeeping behaviors and therefore impact her relationship with her adolescent. Future research on associations between maternal gatekeeping, psychological control, and parent-adolescent relationships may benefit from explorations of these other dimensions of maternal personality, marital quality, and coparenting.

\section{Limitations and directions for future research}

These preliminary explorations of maternal gatekeeping and maternal psychological control alert us to further important inquiry about the processes within families, particularly those between parents and those between parent and child. The current assessment focuses on only one period of time, but longitudinal analyses may further elucidate associations between gatekeeping, psychologically controlling behaviors, and parent-child relationship quality. For example, it is possible that there is a reciprocal process of interaction between gatekeeping and maternal psychological control, such that each influences the other over time, suggesting that maternal psychological control may also be implicated in the presence of inhibitory gatekeeping attitudes and behaviors. Or, conversely, it is possible that these are not actually reciprocal interactions, but that one "causes" the other-is it gatekeeping attitudes and behaviors that "cause" psychological control, or is it psychological control that "causes" gatekeeping attitudes and/or behaviors. Questions such as these will be best understood using longitudinal assessments of these variables not represented in the current manuscript.

Second, we note that though this sample is representative of two-parent families in a northwestern community, it is not nationally representative. Third, in the present study we do not measure facilitative gatekeeping. Research to this point indicates that facilitative gatekeeping can have positive influences on father-child interactions (Schoppe-Sullivan et al., 2008); thus a natural next step would be to investigate whether facilitative gatekeeping is also related to controlling childrearing practices. If so, what impact does facilitative gatekeeping have on the mother-child relationship?

Fourth, future research should question if psychological control mediates the association between maternal gatekeeping and the father-child relationship. And fifth, for a more complete assessment of family systems theory fathers should be more directly represented by including not only mother reports of gatekeeping, but also father reports of maternal gatekeeping and/or father-adolescent relationship quality. We note that our sample size precluded our ability to include father reports and still preserve the benefits of testing both the structural and measurement model (see Kline, 2011). Without structural equation modeling, we would not have been able to use percentile corrected bootstrapping analyses for mediation, which allow us to decompose direct, indirect, and total effects, and offer us a more accurate assessment of the statistical significance and accompanying confidence interval with each effect. We note that our assessment of the maternal gatekeeping literature to date demonstrates that fathers rarely report on maternal gatekeeping practices or their partner's maternal gatekeeping 
attitudes. We further note that maternal gatekeeping literature has focused solely on the father-child dyad as the outcome of interest. The current project informs scholars that inhibitory maternal gatekeeping has a potentially deleterious impact on the mother-child dyad as well. Future research using father reports and mother reports in tandem will give us a more complete account of family systems processes.

\section{Conclusion}

In conclusion, does mother really know best? Some mothers may know best, but our research suggests that mothers who control or constrict other family members may be placing the quality of their family relationships at risk. Do these findings suggest that all gatekeepers are "bad" mothers? Certainly not. It is essential to recognize that we have only assessed reports of inhibitory gatekeeping attitudes and behaviors. Further, it is not gatekeeping alone that negatively impacts mother-child relationships. Our findings suggest that the combination of inhibitory gatekeeping and psychological control serve as a double threat against mother-adolescent involvement, and that future research on this aspect of family process is essential.

\section{Acknowledgments}

Data collection for this study was funded by grants to individual investigators and to the collective project. Donors and funding agencies include the following: School of Family Life Endowment (BYU), Family Studies Center Endowment (BYU), Marjorie Pay Hinckley Endowed Chair (BYU), Mary Lou Fulton Endowed Chair in the Social Sciences (BYU), Mentoring Environment Grant (BYU), LB and LW Smith and Family Foundation, Kreutzkamp Family Foundation, Brent and Cheri Andrus Family Trust, and James W. and Carolyn O. Ritchie Supporting Organization.

\section{References}

Adamsons, K. (2010). Using identity theory to develop a midrange model of parental gatekeeping and parenting behavior. Journal of Family Theory and Review, 2(2), 137-148.

Allen, S. M., \& Hawkins, A. J. (1999). Maternal gatekeeping: mothers' beliefs and behaviors that inhibit greater father involvement in family work. Journal of Marriage and Family, 61(1), 199-212.

Amato, P. R., \& Rivera, F. (1999). Paternal involvement and children's behavior problems. Journal of Marriage and Family, 61(2), 375-384.

Arbuckle, J. L. (2010). Amos (version 19.0) [Computer Program]. Chicago: SPSS.

Barber, B. K. (1992). Family, personality, and adolescent problem behaviors. Journal of Marriage and Family, 54, 69-79.

Barber, B. K. (1996). Parental psychological control: revisiting a neglected construct. Child Development, 67, 3296-3319.

Barber, B. K., Stolz, H. E., \& Olsen, J. A. (2005). Parental support, psychological control, and behavioral control: assessing relevance across time, culture, and method. Monographs of the Society for Research in Child Development, 282(70), 1-137.

Baril, M. E., Crouter, A. C., \& McHale, S. M. (2007). Processes linking adolescent well-being, marital love, and coparenting. Journal of Family Psychology, 21(4), $645-654$.

Beutler, I. F., Burr, W. R., Bahr, K. S., \& Herrin, D. A. (1989). The family realm: theoretical contributions for understanding its uniqueness. Journal of Marriage and Family, 51, 805-816.

Broderick, C. B. (1993). Understanding family process: Basics of family systems theory. Thousand Oaks, CA: Sage.

Buhi, E. R., Goodson, P., \& Neilands, T. B. (2007). Structural equation modeling. A primer for health behavior researchers. American Journal of Health Behavior, $31,74-85$.

Cannon, E. A., Schoppe-Sullivan, S. J., Mangelsdorf, S. C., Brown, G. L., \& Sokolowski, M. S. (2008). Parent characteristics as antecedents of maternal gatekeeping and fathering behavior. Family Process, 47(4), 501-519.

Conger, K. J., Conger, R. D., \& Scaramella, L. V. (1997). Parents, siblings, psychological control, and adolescent adjustment. Journal of Adolescent Research, 12, 113-138.

Cox, M. J., Paley, B., \& Harter, K. (2001). Interparental conflict and parent-child relationships. In J. Grych, \& F. Fincham (Eds.), Child development and interparental conflict (pp. 249-272). Cambridge: Cambridge University Press.

Day, R. D., Bean, R., Harper, J., Miller, R., Padilla-Walker, L., Yorgason, J., et al. (2009). Flourishing families research project: A study of family life and child wellbeing. The School of Family Life, Brigham Young University.

Day, R. D., \& Padilla-Walker, L. (2009). Mother and father connectedness and involvement during early adolescence. Journal of Family Psychology, 23(6), 900-904.

DeLuccie, M. F. (1995). Mothers as gatekeepers: a model of maternal mediators of father involvement. The Journal of Genetic Psychology, 156(1), 115-131.

Doyle, \& Markiewicz. (2005). Parenting, marital conflict and adjustment from early- to mid-adolescence: mediated by adolescent attachment style? Journal of Youth and Adolescence, 34, 97-110.

Fagan, J., \& Barnett, M. (2003). The relationship between maternal gatekeeping, paternal competence, mothers' attitudes about the father role, and father involvement. Journal of Family Issues, 24(8), 1020-1043.

Feinberg, M. E. (2002). Coparenting and the transition to parenthood: a framework for prevention. Clinical Child and Family Psychology Review, 5(3), $173-195$.

Feinberg, M. E., Kan, M. L., \& Hetherington, E. M. (2007). The longitudinal influence of coparenting conflict on parental negativity and adolescent maladjustment. Journal of Marriage and Family, 69(3), 687-702.

Futris, T., \& Schoppe-Sullivan, S. J. (2007). Mothers' perceptions of barriers, parenting alliance and adolescent fathers' engagement with their children. Family Relations, 56, 258-269.

Gaunt, R. (2008). Maternal gatekeeping antecedents and consequences. Journal of Family Issues, 29(3), 373-395.

Gray, M. R., \& Steinberg, L. (1999). Unpacking authoritative parenting: reassessing a multidimentional construct. Journal of Marriage and Family, $61,574-587$.

Hawkins, A. J., Bradford, K. P., Palkovitz, R., Day, R. D., Christiansen, S. L., \& Call, V. C. (2002). The inventory of father involvement: a pilot study of a new measure of father involvement. Journal of Men's Studies, 10, 183-196.

Herzog, M. J., Umana-Taylor, A. J., Madden-Derdich, D. A., \& Leonard, S. A. (2007). Adolescent mother's perceptions of fathers' parental involvement: satisfaction and desire for involvement. Family Relations, 56(3), 244-257.

Hu, L., \& Bentler, P. M. (1999). Cutoff criteria for fit indexes in covariance structure analysis: conventional criteria versus new alternatives. Structural Equation Modeling, 6, 1-55.

Jaccard, J., Dittus, P. J., \& Gordon, V. V. (1996). Maternal correlates of adolescent sexual and contraceptive behavior. Family Planning Perspectives, 28(4), 159-165. 
Kim, J., \& Cicchetti, D. (2004). A longitudinal study of child maltreatment, mother-child relationship quality and maladjustment: the role of self-esteem and social competence. Journal of Abnormal Child Psychology, 32(4), 341-354.

Kline, R. B. (2011). Principles and practice of structural equation modeling (3rd ed.). New York: NY: The Guilford Press.

Krishnakumar, A., Buehler, C., \& Barber, B. K. (2003). Youth perceptions of interparental conflict, ineffective parenting, and youth problem behaviors in European-American and African-American families. Journal of Social and Personal Relationships, 20, $239-260$.

Laursen, B., \& Collins, W. A. (2009). Parent-child relationships during adolescence. In R. M. Lerner, \& L. Steinberg (Eds.), Handbook of adolescent psychology (3rd ed.). Contextual influences on adolescent development, Vol. 2 (pp. 3-42). New York: Wiley.

Lee, M., Bartholomew, M. K., Schoppe-Sullivan, S. J., \& Kamp Dush, C. M. (2011, April). Which mothers are gatekeepers? The role of enduring personal characteristics versus current mental state. Poster presented at the biennial meeting of the Society for Research in Child Development, Montréal, Quebec, Canada.

Lindsey, E. W., \& Caldera, Y. M. (2006). Mother-father-child triadic interaction and mother-child dyadic interaction: gender differences within and between contexts. Sex Roles, 55, 511-521.

MacKinnon, D. P. (2008). Introduction to statistical mediation analysis. New York, NY: Taylor \& Francis Group, LLC.

McBride, B. A., Brown, G. L., Bost, K. K., Shin, N., Vaughn, B., \& Korth, B. (2005). Paternal identity, maternal gatekeeping, and father involvement. Family Relations, 54, 350-372.

McHale, J. (2009). Shared child rearing in nuclear, fragile, and kinship family systems: Evolution, dilemmas, and promise of a coparenting framework. Strengthening couple relationships for optimal child development. Washington, DC: American Psychological Association.

Melby, J., Conger, R., Book, R., Rueter, M., Lucy, L., Repinsky, D., et al. (1998). The Iowa family interaction rating scales. Ames, IA: Institute for Social and Behavioral Research, Iowa State University.

Melby, J. N., Conger, K. J., \& Puspitawati, H. (1999). Insider, participant observer, and outsider perspectives on adolescent sibling relationships. In F. M. Berardo, \& C. L. Shehan (Eds.), Contemporary perspectives on family research. Through the eyes of the child: Re-visioning children as active agents in family life, Vol. 1 (pp. 329-351). Stanford, CT: JAI Press.

Melby, J. N., Hoyt, W. T., \& Bryant, C. M. (2003). A generalizability approach to assessing the effects of ethnicity and training on observer ratings of family interactions. Journal of Social and Personal Relationships, 20, 171-191.

Minuchin, S. (1974). Families and family therapy. Cambridge, MA: Harvard University Press.

Minuchin, P. (1985). Families and individual development: provocations from the field of family therapy. Child Development, 56(2), 289-302.

Pettit, G. S., \& Laird, R. D. (2002). Intrusive parenting: how psychological control affects children and adolescences. In B. K. Barber (Ed.), Psychological control and monitoring in early adolescence: The role of parental involvement and early child adjustment (pp. 97-123). Washington, DC: American Psychological Association.

Pettit, G. S., Laird, R. D., Dodge, K. A., Bates, J. E., \& Criss, M. M. (2001). Antecedents and behavior-problem outcomes of parental monitoring and psychological control in early adolescence. Child Development, 72(2), 583-598.

Pleck, J. H. (2010). Paternal involvement: revised conceptualization and theoretical linkages with child outcomes. In M. E. Lamb (Ed.), The role of the father in child development (5th ed.) (pp. 58-93). Hoboken, NJ: John Wiley \& Sons, Inc.

Pleck, J. H., \& Hofferth, S. L. (2008). Mother involvement as an influence on father involvement with early adolescents. Fathering, 6(3), 267-396.

Preacher, K. J., \& Hayes, A. F. (2008). Asymptotic and resampling strategies for assessing and comparing indirect effects in multiple mediator models. Behavior Research Methods, 40, 879-891.

Puhlman, D. J., \& Pasley, K. (2010). Conceptualizing maternal gatekeeping. Paper presentation at the National Council on Family Relations Theory Construction and Research Methods Conference.

Rathert, J., Fite, P. J., Gaertner, A. E., \& Vitulano, M. (2011). Associations between effortful control, psychological control, and proactive and reactive aggression. Child Psychiatry E Human Development, 42(5), 609-621.

Roy, K. M., \& Dyson, O. L. (2005). Gatekeeping in context: babymama drama and the involvement of incarcerated fathers. Fathering, 3(3), 289-310.

Sano, Y., Richards, L. N., \& Zvonkovic, A. M. (2008). Are mothers really "gatekeepers" of children? Rural mothers' perceptions of nonresident fathers' involvement in low-income families. Journal of Family Issues, 29(12), 1701-1723.

Scaramella, L. V., Conger, R. D., Spoth, R., \& Simons, R. L. (2002). Evaluation of a social contextual model of delinquency: a cross-study replication. Child Development, 73, 175-195.

Schoppe-Sullivan, S. J., Cannon, E. A., Brown, G. L., Mangelsdorf, S. C., \& Sokolowski, M. S. (2008). Maternal gatekeeping, coparenting quality, and fathering behavior in families with infants. Journal of Family Psychology, 22(3), 389-398.

Soenens, B., Elliot, A. J., Goossens, L., Vansteenkiste, M., Luyten, P., \& Duriez, B. (2005). The intergenerational transmission of perfectionism: parents' psychological control as an intervening variable. Journal of Family Psychology, 19, 358-366.

Soenens, B., Park, S., Vansteenkiste, M., \& Mouratidis, A. (2012). Perceived parental psychological control and adolescent depressive experiences: a crosscultural study with Belgian and South-Korean adolescents. Journal of Adolescence, 35, 261-272.

Soenens, B., Vansteenkiste, M., Duriez, B., \& Goossens, L. (2006). In search of the sources of psychologically controlling parenting: the role of parental separation anxiety and parental maladaptive perfectionism. Journal of Research on Adolescence, 16, 539-559.

Soenens, B., Vansteenkiste, M., Luyten, P., Duriez, B., \& Goossens, L. (2005). Maladaptive perfectionisitic self-representations: the meditational link between psychological control and adjustment. Personality and Individual Differences, 38(20), 487-498.

Teubert, D., \& Pinquart, M. (2010). The association between coparenting and child adjustment: a meta-analysis. Parenting: Science and Practice, $10,286-307$.

Trinder, L. (2008). Maternal gate closing and gate opening in postdivorce families. Journal of Family Issues, 29(10), 1298-1324.

Wang, Q., Pomerantz, E. M., \& Chen, H. (2007). The role of parents' control in early adolescents' psychological functioning: a longitudinal investigation in the United States and China. Child Development, 78(5), 1592-1610.

Wenk, D., Hardesty, C. L., Morgan, C. S., \& Blair, S. L. (1994). The influence of parental involvement on the well-being of sons and daughters. Journal of Marriage and Family, 56(1), 229-234. 